\title{
Movilidad y procesos migratorios de la colectividad chipaya hacia el norte de Chile*
}

\section{Mobility and migratory processes of the Chipaya \\ community towards northern Chile}

\author{
Vivian Gavilán Vega** \\ Universidad de Tarapacá, Chile.
}

Cómo citar este artículo: Gavilán, V. (2019). Movilidad y procesos migratorios de la colectividad chipaya hacia el norte de Chile. Si Somos Americanos. Revista de Estudios Transfronterizos, 19(2), 7-25.

DOI: $10.4067 / \mathrm{S} 0719-09482019000200007$

\section{Resumen}

Se presentan resultados de investigación sobre las movilidades y los procesos migratorios de los chipayas hacia el norte chileno. La pregunta que organiza la reflexión es: ¿cuál es la situación y condición de los inmigrantes que provienen del poblado de Santa Ana (Bolivia) en el norte de Chile? A través de un enfoque cualitativo se entrevistaron a mujeres y a hombres con más de cuatro años de residencia en diferentes localidades. El análisis de los datos informa que los históricos desplazamientos estacionales tienden a ser reemplazados por la permanencia en los pueblos y ciudades. No obstante que mantienen los vínculos con la comunidad de origen, avanzan hacia la desruralización, descampesinación y a la translocalización de las redes sociales de la comunidad hacia los espacios urbanos. De este

* Este artículo forma parte del proyecto titulado: "Estudio de las relaciones de género en las narrativas del pasado en la colectividad aymara del norte chileno", auspiciado por el Concurso Proyectos Mayores de Investigación Científica y Tecnológica Universidad de Tarapacá 2018. Además, se inscribe en el trabajo de investigación que desarrolla la autora como doctoranda del Programa de Doctorado en Antropología y Comunicación del Departamento de Antropología, Filosofía y Trabajo Social, Universitat Rovira i Virgili, Catalunya, España.

** Antropóloga, magíster FLACSO, Quito-Ecuador. Académica, Universidad de Tarapacá. Correo electrónico: viviangav@yahoo.com; vtgavilanv@uta.cl 
modo, se da cuenta de las dinámicas socioeconómicas, socioétnicas y culturales de uno de los pueblos indígenas del sur andino escasamente estudiado en el siglo XXI.

Palabras clave: chipayas, migración transfronteriza, pueblos originarios.

\begin{abstract}
This study presents the results of research conducted on the movements and migratory processes of the Chipaya people towards the Chilean north. The main focus of the research is the situation and condition of migrants in northern Chile who come from the town of Santa Ana (Bolivia). Women and men who had lived in different locations for at least four years were interviewed using a qualitative approach. The data show that historical seasonal displacements have tended to be replaced by permanence in towns and cities. Although the subjects of the study maintain their connections to their community of origin, they have distanced themselves from the rural life and undergone a process of depeasantization and the translocalization of the community's social networks in urban spaces. The study reveals the socio-economic, socio-ethnic and cultural dynamics of one of the indigenous peoples of the Andean south that has received little attention from scholars in the 21st century.

Keywords: Chipayas, cross-border migration, indigenous peoples.
\end{abstract}

\title{
Introducción
}

Los desplazamientos poblacionales en territorios que comprenden diversos nichos ecológicos en el sur andino son de larga data. Movimientos de grupos que se trasladan de la cordillera de los Andes hacia la costa del Pacífico y viceversa han sido documentados por historiadores y arqueólogos (Acosta, 2001; Cereceda, 2010; Muñoz, 2011; Uhle, 1922; Wachtel, 1997, 2001). Estos han señalado que el pueblo llamado Uros en tiempos coloniales fue confinado al territorio que actualmente ocupa por otros pueblos originarios, como resultado de los cambios generados tanto en la fase final de la expansión inca como por la invasión española. En efecto, es probable que este acoso hacia los urus sea anterior al arribo de los españoles, y continuado durante la colonia y república, debido a que habrían perdido parte de su territorio como consecuencia de un proceso de persecución y arrinconamiento. A inicios del siglo XX, Uhle informa que

Los uros se pueden considerar como los aborígenes de la altiplanicie boliviana. De los nombres geográficos, basados en palabras y terminaciones de su lengua, se puede derivar el área que ocuparon en tiempos más antiguos. Esta disponía de una extensión mucho mayor de la que aparece por las informaciones existentes y parece que aun en el siglo XVI, ellos formaban algunos nombres en distritos, donde ahora 
no se encuentra ningún uro. Según parece se extendieron en algún tiempo remoto de la costa pacífica hasta el río de Cotagaita, y de la parte superior del río Loa o todavía desde más al sur, hasta el norte del lago Titicaca. (1922, pp. 10-11)

Así, sugiere que los grupos que habitaban en torno a las islas fueron llamados urus, y que también incluía a aquellos que se ubicaban "en la costa pacífica entre Arica y Tarapacá, al sur del lago en Pucarani y que hablaban su idioma” (Uhle, 1922, p. 8). Al momento de su exploración, identifica una "población de unos 500 uros en Chipaya, al norte del salar de Coipasa, siendo este su centro más importante" (Uhle, 1922, p. 8). Aclara que las áreas ocupadas por urus y puquinas eran bastante diferentes, lo mismo que sus lenguas.

Actualmente los uru-chipayas de la comunidad de Santa Ana se ubican en territorio boliviano y han convivido de manera pacífica con las comunidades aymaras de Isluga y Cariquima, situadas solo a $50 \mathrm{~km}$, aproximadamente, en territorio chileno, distinguiéndose étnicamente hasta el presente (Gavilán, 2015); en contraste con la manera conflictiva que han cohabitado con los aymaras de Huachacalla, debido a disputas sobre deslindes territoriales (Wachtel, 1997). ${ }^{1}$ Aunque la antigua frontera peruano-boliviana que deslindaba a Oruro (Bolivia) de Tarapacá (Perú hasta 1879 y Chile hasta el presente) prácticamente se mantuvo, varias comunidades altiplánicas aymaras se dividen entre ambos países. A lo largo del siglo XX, las familias del pueblo Santa Ana se trasladaron hacia los valles occidentales con la finalidad de complementar su economía campesina, sorteando las fronteras nacionales para emplearse temporalmente como jornaleros agrícolas en los pueblos precordilleranos. Sergio González (2009) señala que con posterioridad al conflicto bélico que produjo la explotación del nitrato, la frontera entre Chile y Bolivia fue manejada en un contexto de integración, por lo menos hasta el término del ciclo de expansión del salitre (1930).

En términos generales, se puede afirmar que Chile tuvo fronteras con Bolivia expeditas y seguras para el tránsito de personas (como fue el caso de los enganches a las oficinas salitreras) y de bienes (como fue el caso del intercambio de productos andinos con aquellos llegados al litoral a través del cabotaje), pero ello no significó que estuvo exento de litigios tanto en localidades bien determinadas como en amplias zonas. (González, 2009, p. 72)

En la actualidad, el control de las fronteras se ha acentuado. El aumento de la población inmigrante en Chile proveniente de otros países latinoamericanos ha crecido notablemente. Por ello, el Estado chileno ha comenzado a restringir el paso por el sur del Perú, generalmente utilizado por familias de escasos recursos para el ingreso al país. Esto ha conducido a los migrantes a buscar una alternativa por la frontera chileno-boliviana de alto Tarapacá. Los mecanismos para frenar el ingreso de inmigrantes han aumentado, lo cual ha tenido consecuencias directas en la movilidad de las familias chipayas hacia Chile. Hasta

1 Hasta hoy los pleitos entre aymaras de Huachacalla y chipayas de Santa Ana aparecen en la memoria de las/os entrevistadas/os y se mantiene como foco conflictivo. 
fines del siglo pasado, el control aduanero y de la policía migratoria era flexible, ya que no disponía de la infraestructura ni del personal como el que cuenta actualmente desde hace 15 años. El patrón histórico de las migraciones cíclicas ha ido enfrentando barreras que obstaculizan el ir y venir, lo que ha conducido a una mayor permanencia en las ciudades del norte chileno. Sin duda, a ello se suman las condiciones económicas y sociales diferenciales entre Bolivia y Chile, valoradas por las familias chipayas; no obstante, mantienen vínculos estrechos con su comunidad de origen.

En el contexto de las desigualdades sociales estructurales que caracterizan al sur andino, los chipayas en Chile son vulnerables por su condición étnica, por su nacionalidad y por su estatus inmigratorio; especialmente las personas que no cuentan con residencia temporal, pues se desempeñan como trabajadores indocumentados. A pesar de esto, las prácticas desplegadas por las familias chipayas para integrarse a la sociedad regional y las reflexiones que elaboran como ciudadanos y como pueblo originario expresan un manejo consciente de las reglas del juego que imponen los Estados-naciones modernos. Las conversaciones sostenidas con mujeres y hombres chipayas residentes en la ciudad de Alto Hospicio y en las localidades de La Tirana y Pintados, ubicadas en la actual región de Tarapacá, muestran a personas con capacidad para sortear obstáculos y para buscar soluciones a sus problemas inmediatos. A pesar de la discriminación negativa que experimentan tanto por la sociedad nacional chilena como por los aymaras, se desenvuelven activamente entre relaciones interétnicas e internacionalidades.

Aún no contamos con estadísticas confiables que nos informen sobre la magnitud del fenómeno migratorio de los chipayas en Chile. Por otra parte, los estudios cualitativos que se refieren a su inserción en la sociedad regional son escasos. Este trabajo intenta aportar antecedentes en este sentido. Se trata de describir a la colectividad chipaya como inmigrantes en el norte del país y observar si siguen los mismos procesos de cambios que han afectado a los aymaras en Chile. Esto es, la desagrarización, descampesinización y desruralización de familias que residieron históricamente en las localidades del interior, producto de los procesos de integración a los mercados regionales y a la sociedad nacional. Asimismo, en el texto se busca caracterizar la translocalización de las familias en las ciudades; es decir, describir la articulación que los chipayas realizan entre la localidad de origen y los nuevos asentamientos urbanos a través de las redes de parentesco. La noción de translocalidad provee una perspectiva que puede iluminarnos sobre el proceso de transformaciones socioeconómicas, sociopolíticas y socioculturales que han experimentado las familias chipayas, el que ha sido denominado como poscomunalidad. Este fenómeno alude a los cambios que han conducido a procesos de desruralización (por las emigraciones y movilidad practicada), desagrarización (por el cambio del patrón de ingresos), descampesinización (por la nueva organización económica adoptada) y translocalización (por la alteración de los patrones de sus relaciones sociales) (Carrasco y González, 2014; Gundermann y González, 2008). En este sentido, se presentan resultados de una investigación que siguió un enfoque cualitativo 
que buscó conocer los procesos étnicos y nacionales, cuyo trabajo de campo se realizó durante los años 2006-2010 en la actual Región de Tarapacá.

\section{La colectividad chipaya de Santa Ana}

La comunidad uru-chipaya habita el salar de Coipasa, el que administrativamente corresponde al municipio indígena originario Chipaya, tercera sección de la provincia Sabaya. El municipio se encuentra ubicado a $204 \mathrm{~km}$ de la capital del departamento de Oruro, al norte de dicho salar y al sur del "eje acuático", y está dividido en cuatro ayllus: Manazaya, Aransaya, Wistrullani y Ayparavi. Los chipayas de los diferentes ayllus tienen una doble residencia dentro del territorio chipaya: por un lado, cuentan con una vivienda en el pueblo Santa Ana de Chipaya (excepto en el caso del ayllu Ayparavi), donde se encuentran las unidades educativas y otras instituciones de intermediación con el Estado; y por otro, cuentan con estancias en los ayllus, cercanas a los terrenos en los que desarrollan sus actividades productivas (Pachaguaya, Rivera Cusicanqui, Riveros, Zilvetty y Campos, 2018). Es un territorio semidesértico, en la zona altiplánica, a una altura de 4.000 kilómetros sobre el nivel del mar. Las aguas del río Lauca, que desembocan hacia el oriente, permiten actividades agrícolas menores y regar pequeñas zonas de pastales para la crianza de llamas y ovejas.

Según el censo de 2001 de Bolivia, el cantón de Chipaya registraba una población de 1.814 habitantes, de los cuales 943 eran hombres y 841 eran mujeres, y estaba conformado de 855 viviendas (CEPAL-CELADE, 2005). Un nuevo censo, de 2012, indicó que para entonces 2.003 personas vivían en el cantón, de las cuales el 49,83\% eran mujeres y el 50,17\% eran hombres (INE, 2012). Así, se puede constatar un pequeño aumento poblacional, lo cual es un indicador de cierto equilibrio demográfico, especialmente de género.

El pueblo chipaya forma un pequeño enclave en el interior de una vasta zona aymara y, de acuerdo con Wachtel (1997), sería el último testimonio de la etnia uru (ver Figura $\mathrm{N}^{\circ}$ 1). 
Figura $N^{\circ} 1$ : Mapa del extremo norte de Chile

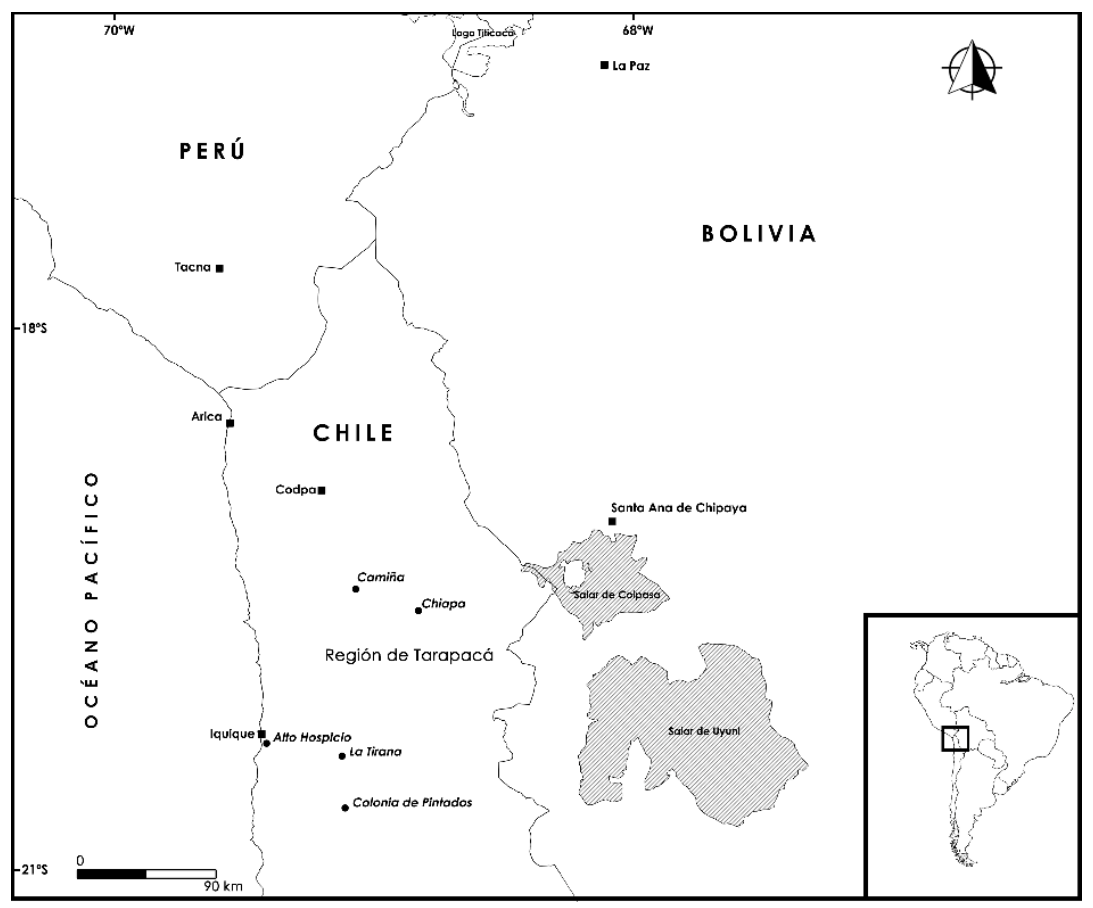

Fuente: elaboración propia.

Hasta la década de 1980, su sistema económico asociaba esencialmente la cría de animales con la agricultura de quínoa. Como complemento, la pesca y la caza formaba parte de las actividades para el autoconsumo. Si bien debían salir en busca de empleos para satisfacer sus necesidades, estos movimientos solían ser temporales y se dirigían a zonas de ocupación de familias aymaras, tanto de territorios bolivianos como chilenos y a localidades más lejanas como Oruro, los valles de la actual Región de Tarapacá, las oficinas salitreras o Iquique.

Por oposición a sus vecinos, los chipayas se identifican a sí mismos como jas-shoni, es decir, gente de agua, en oposición a los aymaras a quienes clasifican como "hombres secos", afirmando su identidad frente al desprecio de los otros grupos indígenas. La memoria oral registra un pasado en el que las familias chipayas lograron emanciparse de la situación de servidumbre de los aymaras de Huachacalla (Wachtel, 1997). Este mismo autor señala que la condición de Uru explica en gran parte el tipo de relaciones interétnicas que establecen con sus vecinos. Estos los consideran chullpa-puchu o desechos de la era presolar y excluidos de la humanidad actual (Wachtel, 1997, p. 12). Plantea este que el mito andino de los chullpas sugiere que son descendientes directos de una prehumanidad, de una edad anterior a la de los hombres:

Este pueblo de chullpas, seres que, de acuerdo al mito original, poblaban la tierra antes de la aparición del sol. Cuando este surgió, todos los chullpas fueron quemados por el fuego celeste, salvo algunos de ellos que se refugiaron en los 
lagos. De estos sobrevivientes del primer juicio descienden los chipayas, así como los otros urus, últimos testigos en este mundo de una humanidad primordial. (Wachtel, 1997, p. 12)

Gran parte de la bibliografía publicada en el siglo XX caracteriza a este grupo como "primitivo", por su apego a las tradiciones antiguas. Durante la temprana colonia, los urus fueron descritos por los cronistas de esta manera, debido a que se dedicaban a pescar en las orillas de los ríos y lagos en los que habitaban, a diferencia de otros grupos que pastoreaban o que practicaban la agricultura. Los urus, por su condición socioeconómica, tributaban de manera distinta a los otros grupos étnicos, y para algunos investigadores es posible que esta condición inferior contribuyó a que su lengua se mantuviera. Arnold y Yapita (2002) argumentan que las fuentes coloniales, así como algunas republicanas, mencionan a un pueblo llamado uru en las riberas del lago Titicaca como un grupo cuya subsistencia se basaba principalmente en la pesca, y que por tanto se lo consideraba especialmente incivilizado, y de poca valía en la economía global. La antigüedad de sus costumbres llamó la atención de Alfred Metraux, quien visitó la comunidad en 1936. Desde una perspectiva evolucionista, este interpreta a los uru-chipayas como exponentes de la edad primitiva prehispánica: "Vive en Chipaya una raza primitiva de gentes que casi no mantiene contacto alguno con otros pueblos del altiplano. Sus vestidos, que pueden remontarse al siglo XV, siguen siendo tan idénticos como los que cubren sus chullpas" (Metraux cit. en Pauwels, 1998, p. 60).

Metraux describe de manera particular las ceremonias llenas de costumbres paganas, en las que la adoración de ídolos superaba a las prácticas andino-cristianas. Este investigador planteó que los chipayas constituían una ventana hacia el pasado y que sus costumbres y tradiciones actuales eran las de los aymaras coloniales. Considera a los chipayas como una tribu aymara que por la situación de aislamiento se ha escapado de la influencia de la modernización (Metraux, 1967: Metraux cit. en Pauwels, 1998).

Las referencias hablan de un pueblo relictual que realiza desplazamientos temporales hacia los valles occidentales, pampa salitrera o ciudades de la costa del norte chileno (Acosta, 2001; Cereceda, 2010; Celis, s. f.; Cerrón-Palomino, 2006; Lara Barrientos, 2012; Metraux, 1967; Muñoz, 2011; Uhle, 1922; Wachtel, 1997). ${ }^{2}$ Pauwels (1998) cita a Posnansky (1937) para señalar que, de no haberse presentado la crisis del salitre, los chipayas hubieran emigrado definitivamente, dejando de ser chipayas. Cerrón-Palomino (2006) argumenta que la precariedad de su economía obliga a los chipayas a buscar fuentes de ocupación fuera de su comunidad y que los varones se movilizan temporalmente hacia los valles precordilleranos de Chile. Cereceda (2010) señala, también, que muchos chipayas se aventuran hacia Chile a realizar trabajos temporales en las chacras de Chiapa, Camiña y otros valles y, por lo menos, hace unos 30 años todavía había enclaves chipayas en el ayllu

2 Un excelente trabajo a consultar sobre bibliografía relacionada con la lengua y cultura chipaya es el de Sabine Dedenbach-Salazar Sáenz (2007). 
Isluga, hoy territorio chileno. Agrega que la historia oral muestra que los chipayas parecen haber dominado en el pasado un paisaje mucho más amplio que el que hoy habitan, que se extendía, posiblemente, hasta los bordes mismos del océano Pacífico. Por su parte, Lara Barrientos (2012) afirma que antes de la apertura de la educación secundaria en el poblado Chipaya, muchos jóvenes se trasladaban a Chile a cursar estudios secundarios. Un sacerdote franciscano, hoy párroco de la Región de Tarapacá que convivió en esta comunidad, sostiene que el principal motivo para el desplazamiento es tener oportunidades de trabajo. Un joven chipaya, trabajador de las parcelas de Pintados en esta misma región, declara que son los jóvenes los que más vienen a trabajar a Chile por temporadas, muchos de los cuales desean quedarse permanentemente.

Muñoz (2011) indica que el paso hacia Chile de los chipayas se produce por las localidades aymaras fronterizas (Isluga y Cariquima) y que la permanencia de estos puede ser temporal, lo que corresponde a quienes están por períodos breves de trabajo en la agricultura de temporada; o puede ser definitiva. Quienes solicitan los permisos legales los hacen en el paso fronterizo de Colchane como turistas, con el propósito de obtener el permiso de residencia. Los desplazamientos que realizan los habitantes de la colectividad chipaya desde Santa Ana hacia la zona occidental de los Andes-continúan activos hasta hoy, pero el contexto socioeconómico, sociopolítico y sociocultural no es el mismo que imperó a lo largo del siglo XX.

\section{Inmigración de los chipayas en Chile en el siglo XXI}

Debido a las condiciones estructurales en las que se desenvuelve el campesinado rural del sur andino, en general, y las familias chipayas, en particular, la emigración de estas hacia los centros urbanos del norte chileno constituye una estrategia para su reproducción. Los migrantes afirman que deben salir de su pueblo en busca de mejoras para su familia, dada la presión que existe sobre la tierra. Uno de ellos nos informa sobre las razones por las cuales históricamente las personas toman la decisión de emigrar:

(...) Antes nuestros abuelos siempre venían a hacer canje con la mercadería, con lana, a Chiapa; a veces creo que iban también a Calama, también venían... además del terreno donde nosotros estamos en Chipaya, estamos muy descuidados... la gente crece más y los terrenos no aumentan, y nosotros no tenemos terrenos como la gente aymara. La gente se multiplica, pero el terreno no se multiplica, entonces muchas parejas vienen a Chile, porque allá van a querer tener su ganadito, su terreno, pero allá no hay vida, entonces se vienen para acá y trabajan como nosotros. (E. Q., hombre, más de 40 años, de La Tirana. Entrevista realizada en marzo de 2007)

La elección de Chile como destino ha sido precedida por experiencias migratorias hacia otras ciudades de Bolivia: 
Las personas salen por problemas económicos, más que todo... y otra cosa es que... que se ve lo mejor para sus hijos, donde está mejor, ahí uno se para. Entonces nosotros vemos que es mejor acá en Chile... porque en Bolivia a hartas partes hemos recurrido, pero no ha sido mejor que acá... allá siempre ha sido más o menos nomás, puro pa' comer nomás, pero pa' algo de ahorro no había. Yo he estado en Santa Cruz, en Chaparé, he estado en Alto Beni, no, yo he visto que no había tanto para vivir, yo preferí para acá... yo creo que eso la gente ve también, por eso están acá mucha gente. (E. Q., hombre, más de 40 años, de La Tirana. Entrevista realizada en abril de 2008)

Si bien los movimientos temporales se justifican por mejorar la vida campesina, la mayor escolaridad de las y los jóvenes va cambiando las aspiraciones de las familias. Por otra parte, la movilidad territorial transfronteriza de antaño se ha restringido. De un tránsito sin control migratorio se pasó al ingreso formal al territorio chileno. Esto, porque sin documentación la permanencia se torna difícil.

(...) Desde mi abuelo, desde mi bisabuelo como unos tres no más venían, pero desde mi abuelo ya venían un poquito más. La generación de mi papá ya casi todos venía. Cuando mi papá era joven, tenía como 17 o 18 años, cuando era soltero, era como una moda, así, venir a Chile a traer algo a la casa... entonces, ya de ahí empezaron, como que vieron que ya ganaba platita todo eso, empezaron a venirse pa' acá... entonces ya empezaron a arreglarse sus documentos ya... ahora, a edad mía, ya casi todos tienen sus documentos. Los que están acá, todos, no he escuchado ninguna persona que son bolivianos ahí, casi todos, no todos tampoco, así... (S. F., hombre, más de 20 años, jornalero de Alto Hospicio. Entrevista realizada en agosto de 2006)

Las personas indocumentadas recurren a la estrategia de cambiar sus apellidos como una forma de ser identificados como aymaras chilenos. De este modo evaden los controles migratorios que realiza la policía en zonas rurales y urbanas. Esta situación es conocida por las familias aymaras, que los emplean para permitir la permanencia y evitar las multas que se aplican a empleadores de indocumentados. Aun cuando esta medida los ha beneficiado, en ocasiones se ven envueltos en conflictos legales, ya que el cambio de nombre constituye un delito y, por lo general, contribuye a generar desconfianzas y a vincularlos con el tráfico de drogas.

(...) Si yo he dado otro nombre, primerito yo dije: "Yo no trabajo aquí, yo no he trabajado aquí, yo vine tres días nomás", dije yo a carabinero. Yo no pensaba decir así, pero mi patrona dijo: "Así vas a decir, que no trabajas aquí; vas a decir que solo tres días has estado aquí”. Eso yo dije también, porque mi patrón me enseñó. (J. F., mujer, más de 20 años, jornalera de Alto Hospicio. Entrevista realizada en febrero de 2006)

En general, todos los entrevistados están informados sobre los mecanismos actualmente existentes para solicitar la residencia temporal y definitiva. Ellos hablan de la amnistía que el 
Estado chileno ha ofrecido para regularizar a la población extranjera que se encuentra trabajando:

(...) Yo creo que están viendo cómo recibir documentos; hay amnistía, por ejemplo, ahora salió amnistía, y ahí se han metido hartas personas igual, entonces yo creo que va a haber después, y van a seguir entrando personas, porque como es cerca, entonces fácil vienen. (T. F., hombre, más de 40 años, empleado municipal de Pozo Almonte. Entrevista realizada en mayo de 2008)

Las redes familiares son importantes para la inserción en el espacio rural y urbano, y esta se da principalmente en el mercado de trabajo campesino. Una mujer que trabaja hoy en Alto Hospicio nos cuenta:

(...) Yo he estado en Alto Hospicio, La Tirana, vine cuando tenía 14e años. Sola viajé. En La Tirana vive mi tío, él me consiguió trabajo, primerito. Trabajé como dos meses y después me vine a Alto Hospicio. (J. F., mujer, más de 20 años, jornalera de Alto Hospicio. Entrevista realizada en mayo de 2006)

El tipo de empleo que consiguen está asociado a la agricultura en quintas, al cuidado de parcelas y o a la ganadería. En las quintas urbanas, el trabajo a destajo implica preparar las verduras para su venta en los terminales agropecuarios: las cortan, las lavan y las atan; la paga que reciben es por atado. En 2010 podían obtener entre $\$ 60.000$ y $\$ 80.000$ semanalmente, lo que promedia en el mes US\$ 450, aproximadamente: "ganábamos dependiendo de lo que sacábamos: a veces 70 o a veces 50; mi marido igual.” (J. F., mujer, más de 20 años, jornalera de Alto Hospicio. Entrevista realizada en febrero de 2006).

En estas faenas se inician como peones agrícolas, especialmente para patrones aymaras de valles y quintas urbanas. Luego, pueden pasar a cuidar parcelas, con lo cual se les retribuye con vivienda y permiso para producir en pequeñas chacras:

(...) Hace 12 años nosotros también estamos acá viviendo, cuidando las parcelas ...la estoy cuidando yo, no nos está pagando... él está pagando la luz... entonces yo saco con la luz el agua, la saco del pozo con el generador eléctrico; entonces yo saco agua y hago mi chacra para vender mercadería algo; yo soy de la verdura, del cilantro... ahí en las quintas en Hospicio, ahí están los chipayas; pocos son los chilenos que trabajan para vender verduras, los del pueblo, con eso viven... a medias, están trabajando a medias, con eso viven. (M. Q., mujer, más de 40 años, jornalera de La Tirana. Entrevista realizada en abril de 2009)

La mediería les ha facilitado una mayor permanencia, buscando quedarse con la familia:

(...) Están dos meses, tres meses así... algunos se van un mes y vuelven después... los que se han dado cuenta, se han quedado, ya varios se han ido quedando: ya tienen su casita, ya tienen su camioneta, su casita propia, han construido su casa, con su techo de calamina.

Los inmigrantes han aumentado aquí, en Chile somos muchos, somos muchos chipayas. En Antofagasta son como una comunidad... y acá en Hospicio, también, 
y en La Tirana, también somos varios más... vamos a pelear por la cancha, y compartimos en el partido. (T.Q. comerciante. Entrevista realizada en mayo de 2007)

Así, los empleos que frecuentemente desempeñan son: jornaleros agrícolas, cuidadores de parcelas, medieros, ayudantes de venta en las ferias y obreros municipales para el aseo y ornato. Este último oficio ha sido una alternativa para mujeres y hombres radicados en los pueblos donde la administración municipal se ha expandido.

Sí... no son esos nomás: no sé cuántos seremos, no he contado ahorita. Por allá hay también unas tres o cuatro, por allá también hay unas dos, como ocho seríamos acá en esta feria, ocho familias... pero todas estas están vendiendo verduras. Allá está vendiendo golosinas la señora, ella es también de Chipaya, su marido es de Cariquima de Hospicio, digo también, de ahí de la frontera... así estamos derramados. (I. Q., mujer, más de 30 años, comerciante de Alto Hospicio. Entrevista realizada en mayo de 2009) (ver Figura $\mathrm{N}^{\circ} 2$ )

\section{Figura $\mathrm{N}^{\circ}$ 2: Desplazamientos de familias chipayas hacia pueblos y ciudades tarapaqueños}

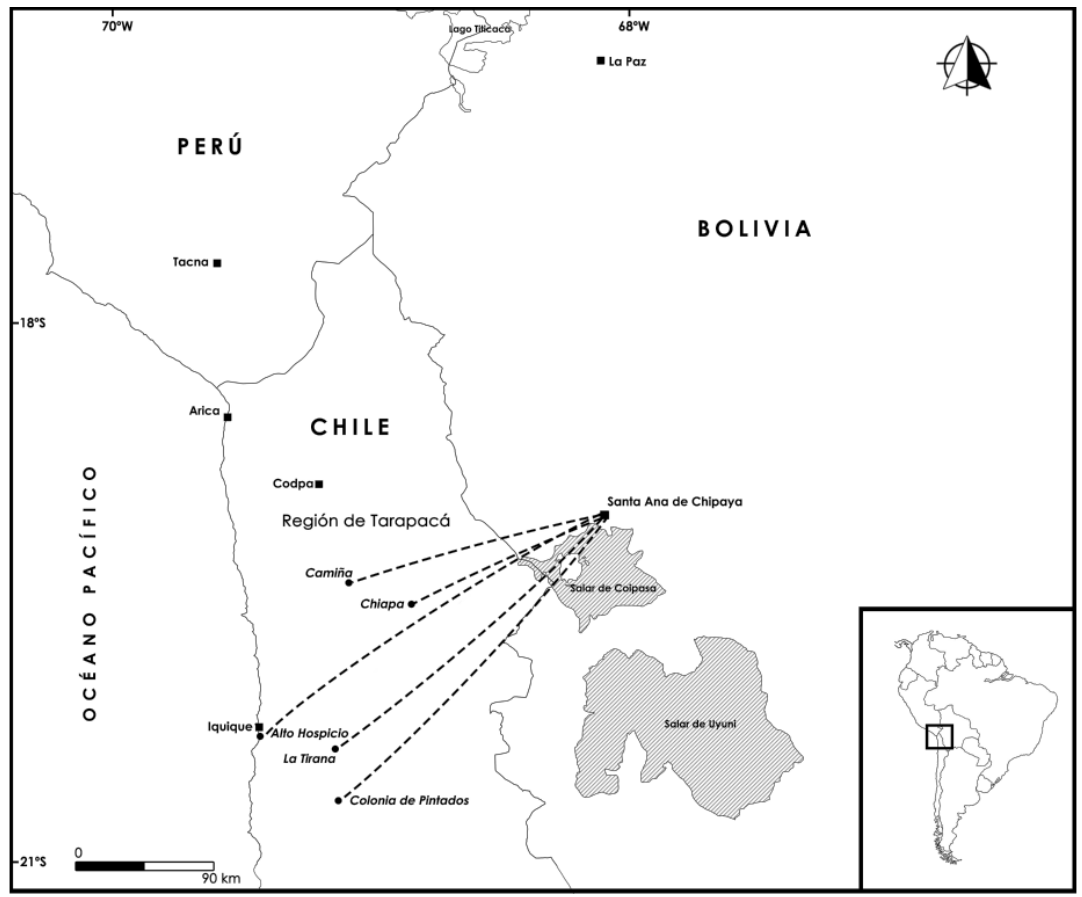

Fuente: elaboración propia.

Se constata que las mujeres chipayas pueden casarse con hombres aymaras y hacer sus vidas como otras mujeres indígenas chilenas, mientras que las uniones de hombres chipayas con mujeres aymaras no son comunes. 
Otra forma de obtener ingresos para los chipayas es participando en grupos musicales. Estos son contratados para animar fiestas de las comunidades aymaras:

(...) Sí, son buenos grupos de tarkas... bailables, les ha gustado a los chilenos... y ellos los pasantes han contratado a dos grupos... antes contrataban a los grupos aymaras, de por ahí de La Paz... y con ellos los hicieron chocar, les hicieron por ahí una entrevista... y los chipayas ganaron, como eran buenos tocadores, eran bailables, buen tono, entonces han gustado a los chilenos. (E. Q., hombre, más de 40 años, empleado municipal de La Tirana. Entrevista realizada en marzo de 2010)

Los entrevistados se refieren a los conflictos territoriales que han tenido con sus vecinos aymaras de Huachacalla, Bolivia, situación que los ha llevado a luchas reivindicativas importantes que permanecen en la memoria colectiva. Argumentan discriminación étnica y social de parte de los aymaras, con quienes han tenido que lidiar por varias décadas. La migración hacia Chile es considerada como una forma de enfrentar mejor esta lucha. La mayor escolaridad de las nuevas generaciones y la experiencia de vida ganada en Chile habrían contribuido a su defensa.

Todavía la gente de Huachacalla quieren quitar terrenos... ahora como los chipayas ya han sabido escribir, leer, se defienden. El año pasado nomás casi se ha declarado una guerra civil. Los chipayas que viven en Chile, carajo, puta ya habían comenzado a sacar sus camisas, ah ustedes están pegando a nosotros a nuestros papás, cómo van a pegarnos ahora... ven si eres hombre, los pararon los de acá y ahora tienen un poco de miedo. Los jóvenes que vuelven de Chile les dicen: "Nosotros somos diferentes, somos diferentes, cómo se les va a ocurrir, si siguen pegando, o quieren quitar la tierra, se la van a ver con nosotros". Así, los que han vuelto de acá han cambiado ánimo. ¡Palabra!, nuestros jóvenes ya se defienden mejor, ahora nos tienen miedo. (E. Q., hombre, más de 40 años, empleado municipal de La Tirana. Entrevista realizada en mayo de 2007)

El proyecto de vida de los chipayas en Chile está asociado a la movilidad social y ellos valoran el sistema educacional estatal:

(...) Por algo estoy aquí... de bueno, el estudio, es más adelantado que en Bolivia... yo he estudiado en Bolivia, pero no tanto como aquí... pero acá yo he visto los niños chicos, mis primos tengo acá, chilenos, primas tengo, son más... digo... no manejan en Bolivia computador como los de básico aquí, mientras acá ya están manejando... por eso digo que es un poco más adelantado, ya están manejando ya la computadora... yo creo que ahora ya recién están entregando, regalando computadores en los colegios... entonces, por ese motivo yo encuentro que es bueno. A mí me ha gustado el estudio, después que tuve mi marido no pude estudiar... no puedo por los niños y todo eso, entonces pero igual siento estudiar, ahí salí de cuarto medio, y con esto que voy a tener, quiero tener mi casita y ahí que crezcan los niños, entonces ahí recién voy a empezar a estudiar, pero ya no en Bolivia, sino que acá estoy pensando estudiar, pero primero tengo que hacer mis papeles todavía, todavía no estoy bien, entonces ahí voy a estudiar, voy a ver 
también. (I. Q., mujer, más de 30 años, comerciante de Alto Hospicio. Entrevista realizada en mayo de 2010)

Así, como indica Muñoz (2011), la migración temporal va cambiando por una mayor permanencia en los poblados del norte del país, para lo cual se buscan diferentes mecanismos administrativos y organizativos. Entre estos se identifican los clubes deportivos, que constituyen una forma de integración donde los chipayas pueden sociabilizar con la población local. Las personas que han logrado el permiso de residencia lideran los clubes y solicitan beneficios a las autoridades locales. A través del deporte establecen relaciones con las autoridades gubernamentales para conseguir beneficios sociales, especialmente canchas de fútbol y viviendas.

(...) En la cancha que está para el lado de La Negra, ahí tienen su cancha. Han entrado de acuerdo con los vecinos de Chile, han entrado en acuerdo con los chilenos, y les han dejado un pedacito de espacio para que jueguen, en cancha, ahí juegan. El año pasado tenía nueve capitanes, entonces hemos solicitado a unos conocidos chilenos, entonces dijeron: “¿Ustedes ya tienen sus documentos chilenos ya?". Entonces le dijimos al alcalde de Pozo Almonte: "Nosotros queremos jugar, queremos compartir, en partido, con los jóvenes ahí, nosotros somos de La Tirana"... Entonces podemos decir que cumple la autoridad. Nosotros somos de Bolivia, pero tenemos aquí nuestros documentos ya, queremos compartir en partido, entonces así dio, para los hombres y las mujeres. (E. Q., hombre, más de 40 años, empleado municipal de La Tirana. Entrevista realizada en enero de 2008)

Las formas que adquieren las competencias difieren de las existentes en las ligas andinas chilenas:

(...) El año pasado... el equipo de La Tirana tiene su propio uniforme de color verde, porque La Tirana es verde por el monte, entonces tenemos el color verde, y tenemos el color amarillo para las mujeres, también tenemos nuestra bandera. El año pasado hicimos campeonato y tuvimos de premio en vez de una copa, tuvimos una olla; entonces ese fue el premio: una olla grande. (T. F., hombre, más de 30 años, jornalero de Pintados. Entrevista realizada en enero de 2008)

Los equipos son conformados principalmente por personas chipayas y participan en campeonatos locales que reúnen a grupos que residen en diferentes pueblos del norte. También hay competencias con grupos aymaras. En este panorama, las familias chipayas migrantes enfrentan discriminación étnica y nacional en el proceso de inserción en Chile. Es así como los aymaras de nacionalidad boliviana los consideran diferentes e inferiores, mientras que los aymaras de nacionalidad chilena los ven como extranjeros y como otro tipo de personas. Por su parte, la población no indígena engloba en una sola categoría a los descendientes de los pueblos originarios:

(...) Sí, la gente de Colchane son (sic) igual que nosotros, morenos, pero más nos discriminan; mientras más gente del sur nos quieren, la gente del sur nos tratan mejor, por lo que somos morenitos, eso... mayoría de la gente del sur que no 
discriminan. Yo trabajaba de empleada antes, cuando estaba estudiando y estaba de vacaciones... entonces ahí yo veía que la gente del sur era más amable con la gente extranjera... me trataban como a una hija... mientras las de acá del interior, ¡uy!, que esto y que lo otro, de todo...nos tratan de todo. (I. C., mujer, más de 30 años, comerciante de Alto Hospicio. Entrevista realizada en mayo de 2009)

(...) También... ¡uy!, a mí cuántas veces a mí me han dicho, que tú, boliviana... por ejemplo, yo vendía en la calle: "Tú, boliviana, ¿por qué estai acá?, te voy a denunciar con Carabineros", decían, "y tú no tienes que estar acá"... entonces yo empezaba a llorar nomás, qué podía hacer... "Yo por mis hijos trabajo, mis hijos son chilenos, mi esposo es chileno", decía yo, porque los Carabineros venían y no me decían nada, nunca me han dicho nada por lo mismo... y eso es lo malo... en otras partes, por ser extranjero a sus hijos no lo han querido recibir... una prima mía estaba andando, y porque su hijo era boliviano no lo quiso recibir, no lo quisieron matricular en la escuela... entonces ella decía. "Por qué, si yo tengo un carné extranjero, yo tengo derecho de vivir acá", mientras en el colegio no los pueden recibir... ahí está, sin estudiar aún, quizás adónde lo va a meter, a lo mejor por los pueblitos lo estarán acogiendo, mientras acá en la ciudad es un poco más duro, más duro. (M. Q., mujer, más de 40 años, comerciante de Alto Hospicio. Entrevista realizada en mayo de 2009)

\section{La vida en la ciudad: hacia la translocalización de la comunidad}

Si bien la movilidad de los chipayas hacia la vertiente occidental de los Andes ha sido históricamente una estrategia para la reproducción socioeconómica de la colectividad, en la actualidad los procesos de integración al mercado laboral regional implican cambios significativos. Las etnicidades y las nacionalidades se articulan para proveer herramientas de adaptación. Ya no se trata solo de migraciones rural-rural, sino rural-urbana con posibilidades de ser definitiva. Sin embargo, los vínculos con la comunidad, con el pueblo de Santa Ana, permanecen. Si bien los aymaras chilenos han experimentado el mismo proceso (Gundermann y González, 2008), la existencia de otra nacionalidad impone barreras que estos no tienen.

Los entrevistados reflexionan sobre su presente a partir de interpretaciones propias respecto de las políticas de los Estados boliviano y chileno, buscando abrir caminos para mejorar su condición. Para ello, la vinculación con la comunidad es importante y el reconocimiento de su grupo como pueblo originario forma parte también de estos procesos.

(...) Que no les quieren dar acceso al mar... escuchan decir a las altas autoridades, que como Bolivia está mal, como la política es mala le da lo mismo, porque la gente no entiende, porque la gente es la mayoría campesina, porque la gente de las ciudades es también del campo, por eso votaron por un presidente de ellos mismos. Pero el presidente es de la gente y no van a aguantar que les hagan nada. Un 
presidente indígena puede mejorar la situación de la población indígena. (E. Q., hombre, más de 40 años, empleado municipal de La Tirana. Entrevista realizada en febrero de 2006)

La nacionalización como estrategia para acceder a vivienda y otros beneficios sociales es pensada por ellos como un dilema. Creen que adoptar la nacionalidad chilena implicaría dejar de ser indígenas bolivianos y por lo tanto perder los beneficios como ciudadanos bolivianos:

Ser chilenos nomás, o ¿ser indígena? ¿Qué es mejor para conseguir un terreno para vivir? Quisiera tener una casa, un terrenito, pero no nos quisieron dar, nos dijeron que teníamos que estar nacionalizados, hay que tramitar nacionalidad, mi carné vence el año 2011. (E. Q., hombre, más de 40 años, empleado municipal de La Tirana. Entrevista realizada en mayo de 2008)

Los datos referidos a la población aymara del norte de Chile indican que la migración ruralurbana no implica el abandono de sus comunidades. Gundermann y González (2008) sugieren que esta colectividad ha formado parte de un proceso de desruralización (debido a las emigraciones y la movilidad practicada), de desagrarización (debido al cambio del patrón de ingresos), de descampesinización (debido a la nueva organización económica adoptada) y de translocalización (debido a la alteración de los patrones de sus relaciones sociales). Aunque la estacionalidad de las migraciones de los chipayas a Chile continúa, ${ }^{3}$ los datos señalan que tienden a lo mismo. Los controles fronterizos impiden el libre tránsito, favoreciendo la permanencia o, al menos, estancias más largas. Pero esto va de la mano con un cambio en los tipos de empleos que oferta principalmente la actividad agropecuaria y el comercio, lo cual incide directamente en transformaciones en el patrón de ingresos y en el consumo. Asimismo, la mayor escolaridad de estos grupos migratorios conduce a la permanencia en los centros urbanos. No obstante, como sugieren Carrasco y González para los aymaras:

Si bien la urbanización acarrea una disminución de la población con residencia permanente en las localidades rurales y la modificación de las estructuras de edades, no se trata de una crisis poblacional; menos de un colapso demográfico que genere un proceso de descomposición; tampoco estamos frente a comunidades incompletas, terminales o agonizantes, simplemente ellas se completan con sus derivaciones hacia otras zonas del sector rural y, principalmente, hacia las ciudades y áreas suburbanas. (2014, p. 227)

Estos autores argumentan que la comunidad ya no se reproduce dentro de sus límites territoriales históricos, puesto que las redes económicas, sociales y culturales traspasan sus antiguas fronteras, prolongándose hacia los distintos sitios donde se encuentren dispersos o transiten sus miembros. Para ello, las relaciones con la comunidad rural de origen son

3 Como señala Muñoz (2011), son los adultos los que optan por movimientos estacionales y las y los jóvenes quienes tienden a la permanencia. 
centrales para la vida en la ciudad, y las familias migrantes inciden hacia la localidad de manera decisiva tanto económica como políticamente. En este contexto, la noción de translocalidad implica que la reproducción económica, social y política de la colectividad chipaya de Santa Ana se basa tanto en la producción local como en los recursos que los migrantes les proveen. Es decir, las relaciones y grupos sociales de la comunidad en territorio boliviano no se agotan en la localidad, sino que incluyen los procesos que activan las familias migrantes hacia Chile. Estas relaciones mantienen influencia bidireccional, incidiendo desde las localidades y los sujetos rurales a los individuos, familias y grupos urbanos, y, en el otro sentido, influyendo desde los espacios y sujetos urbanos hacia las localidades rurales.

El fuerte vínculo con la comunidad de origen se expresa también en la importancia que adquieren las festividades como carnavales, fiestas patronales y los días de muertos. Normalmente, dejan sus actividades laborales en Chile para asistir a estas celebraciones. La comunicación con la familia se produce a través de cartas o mensajes que llevan los parientes y por vía telefónica. Pachaguaya et al. (2018) informan que "el trabajo en Chile les permite una complementariedad e interdependencia económica" (p. 24). Es decir, los procesos migratorios de los chipayas en Chile no pueden ser clasificados de forma inequívoca como migraciones estacionales o permanentes. Estos autores registran varios testimonios que confirman la tesis de la articulación de los lugares de origen con los de destino para definir sus vidas. Un ejemplo de ello son los retornos para el cumplimiento de cargos comunales que les permiten mantener su acceso a la tierra:

Solamente por un año viene aquí a prestar cargo, porque los residentes no pueden, porque tienen continuo trabajo allá, solamente ellos pasan la autoridad, que es más pesado, ¿no ve? Jilaqata es la autoridad más pesada, eso es lo que tiene más cargo y más gasto. (Pachaguaya et al., 2018, p. 27)

Las responsabilidades comunitarias se mantienen como parte de los modos de vida y la articulación campo-ciudad es comprendida por estos autores como manifestación de las relaciones de complementariedad e interdependencia que entran en juego para el funcionamiento y sostenibilidad del territorio. Los procesos de translocalización de las redes sociales es también reseñada por estos, quienes señalan que:

Las redes sociales tejidas tanto con familiares y parientes como con vecinos posibilitan participar en organizaciones sociales que buscan resolver el tema de la propiedad. En el caso de Alto Hospicio, esto se vincula con el acceso a la vivienda a partir de lo que en Chile se denomina las tomas de terreno. (Pachaguaya et al., 2018, p. 28) 


\section{Reflexiones finales}

Los antecedentes expuestos muestran procesos de adaptación de la comunidad chipaya al contexto actual de modernización y globalización económica y cultural occidental que ha experimentado el norte chileno. La práctica de movilidad estacional para complementar recursos es de larga data, constituyéndose en una experiencia habitual hasta fines del siglo pasado. El empleo en los valles en períodos de mayor demanda de trabajo del ciclo agrícola o en las oficinas salitreras ha dado paso a trabajos más diversificados, propios de la oferta laboral regional actual. Es así como los chipayas han ido ocupando los nichos que han dejado los aymaras en el sector agropecuario, además de incursionar en el comercio; es decir, han seguido los pasos de los procesos del conjunto de los pueblos originarios de la región, adaptándose a través de la articulación de su forma de vida en sus comunidades de origen con las nuevas exigencias de los espacios urbanos complejos.

Si comparamos su comportamiento con las dinámicas de los aymaras, los chipayas no disponen de los mismos recursos agrícolas y ganaderos, y su condición de extranjeros les impide acceder a subsidios estatales sin nacionalizarse; en consecuencia, sus ingresos tienden a ser inferiores. La histórica desterritorialización que han experimentado producto de la imposición de nuevas fronteras se agudiza debido la violencia ejercida por los Estados-naciones modernos sobre sus vínculos con el territorio ancestral, en la medida en que se les considera como extranjeros en sus propios territorios. En el caso de Chile, su condición de indocumentados los expone a persecuciones, expulsiones o encarcelamientos. Adicionalmente, la discriminación por parte de los aymaras, tanto bolivianos como chilenos, genera obstáculos adicionales que las familias deben sortear. A pesar de esto, existe un manejo de la frontera como centro vital de referencia (Morales cit. en Tapia, 2014). La vecindad (pacífica y conflictiva) con sus vecinos de larga data muestra, al mismo tiempo, un proceso de apropiación del territorio que trasciende los límites normativos para habitarlo y vivirlo con las ventajas y desventajas que esto implica.

En lo que va corrido del siglo XXI, la tendencia a adoptar la residencia legal en Chile ha ido aumentando, sin que ello signifique desvincularse de la comunidad de origen. Las decisiones de continuar en las ciudades chilenas se relacionan con una mejor y mayor integración al mercado laboral regional del norte de Chile. Para mujeres y hombres significa obtener ingresos monetarios que no logran conseguir en Bolivia, debido a las brechas salariales existentes entre ambos países. Así lo indican también los testimonios de personas entrevistadas residentes en Iquique por Pachaguaya et al. (2018). El acceso a los sistemas escolar, de salud y de vivienda es concebido como ascenso social y como una estrategia para mejorar el estándar de vida personal, familiar y comunal. La lengua chipaya es hablada en la vida cotidiana, aunque va disminuyendo a medida que aumentan los niveles de escolaridad. Si bien tienden a la convergencia y homogeneización cultural, ligada a la cultura mediática, al mercantilismo generalizado y al consumismo, los chipayas

continúan con la voluntad de distinguirse tanto desde el punto de vista étnico como

Si Somos Americanos. Revista de Estudios Transfronterizos 23 
nacional en un contexto de nuevas relaciones interétnicas e internacionales, articulando los recursos comunitarios de origen como los conseguidos en los lugares de destino.

Las familias residentes en Chile son centrales para acoger a los nuevos inmigrantes, pero también para organizarse como colectividad diferenciada étnicamente. Son ellas las que facilitan la inserción en la sociedad nacional. La estrategia de obtener la nacionalidad chilena para mejorar sus actuales condiciones de vida implica dejar de ser ciudadanos bolivianos, lo cual no es fácil para ellos, ya que su intención es complementar actividades, tal como lo hacían en antaño. Tanto en Chile como en Bolivia, los chipayas configuran un conjunto social perteneciente a las sociedades nacionales, pero ello no implica necesariamente la ciudadanía plena, aunque sus vínculos históricos con el territorio en el que han habitado durante los últimos cinco siglos avalan el derecho a formar parte de ambos Estados.

\section{Referencias}

Acosta, O. (2001). La muerte en el contexto uru: el caso chipaya. Chungará, 33, 259-270.

Arnold, D. y Yapita, J. (2002). Las wawas del inka. Hacia la salud interna intercultural en algunas comunidades andinas. La Paz: ILCA.

Carrasco, A. M. y González, H. (2014). Movilidad poblacional y procesos de articulación rural-urbano entre los aymara del norte de Chile. Si Somos Americanos, 14(2), 217231.

Celis, N. (s. f). El rumor de una migración en silencio: la sobrevivencia uru-chipaya. Recuperado de: http://www.corredordelasideas.org/docs/ix_encuentro/ nicolas_celis.pdf

CEPAL-CELADE (2005). Los pueblos indígenas de Bolivia: diagnóstico sociodemográfico a partir del censo del 2001. Santiago: CEPAL. Recuperado de: https://repositorio.cepal.org/bitstream/handle/11362/3566/1/S2009029_es.pdf

Cereceda, V. (2010). Una extensión entre el altiplano y el mar. Relatos míticos chipaya y el norte de Chile. Estudios Atacameños, 40, 101-130.

Cerrón-Palomino, R. (2006). El Chipaya o la lengua de los hombres de agua. Lima: Fondo Editorial Pontificia Universidad Católica del Perú.

Dedenbach-Salazar Sáenz, S. (2007). The andean uru-chipaya language (state of research and bibliography 2007). Recuperado de: http://dobes.mpi.nl/project_data/chipaya/ Chipaya\%20state\%20of\%20research\%20and\%20bibliography\%20\%28Dedenbach, $\% 2019-05-07 \% 29$.pdf

Gavilán, V. (2015). Ser indio y ciudadano en el norte chileno: etnicidad y estatus de pertenencia a la comunidad nacional y política. Revista de Geografía Norte Grande, 60, 63-77. 
González, S. (2009). La presencia boliviana en la sociedad del salitre y la nueva definición de la frontera: auge y caída de una dinámica transfronteriza (Tarapacá 1880-1930). Chungará, 41(1), 71-81. Recuperado de: https://dx.doi.org/10.4067/S071773562009000100005

Gundermann, H. y González, H. (2008). Pautas de integración regional, migraciones, movilidad y redes sociales en los pueblos indígenas de Chile. Universum, 23, 82115.

INE. (2012). Resultados Censo de Población y Vivienda. Bolivia. (En línea). Recuperado de: http://datos.ine.gob.bo/binbol/RpWebEngine.exe/Portal?BASE=CPV2012COM\&la ng=esp

Lara Barrientos, M. (2012). Discriminación hacia minorías étnicas: el caso de los urus del lago Poopó. Tinkazos, 15(31), 57-78. Recuperado de: http://www.scielo.org.bo/scielo.php?script=sci_arttext\&pid=S19907451201200010 0004\&lng=es\&nrm=iso>. ISSN 1990-7451

Metraux, A. (1967). Religions et magies indiennes d'Amérique du sud. París: Gallimard.

Muñoz, C. (2011). Los urus-chipaya en Chile. Revista de Ciencias Sociales, 27, 7-20.

Pachaguaya, P., Rivera Cusicanqui, S., Riveros, G., Zilvetty, A. y Campos, S. (2018). Sistematización de la experiencia migratoria de la población Chipaya en Chile. Informe Final. (En línea). Recuperado de: http://chipaya.org/?p=1945

Pauwels, G. (1998). Los últimos chullpas, Alfred Metraux en Chipaya (1931). Eco Andino, 6(3), 7-29.

Posnansky, A. (1937). Antropología y sociología de las razas interandinas y de las regiones adyacentes. La Paz: Renacimiento.

Tapia, M. (2014). Extranjeros fronterizos en las regiones extremas de Chile: entre migración y circulación 1990-2014. En N. Rojas, y J. Vicuña (Eds.). Migración y trabajo. Estudio y propuestas para la inclusión sociolaboral de migrantes en Arica (pp.31-54). Arica: Ciudadanía Global y OIM.

Uhle, M. (1922). Fundamentos étnicos de Arica y Tacna. Quito: Imprenta Banco Central.

Wachtel, N. (1997). Dioses y vampiros. Regreso a Chipaya. México D. F.: Fondo de Cultura Económica.

Wachtel, N. (2001). El regreso de los antepasados. Los indios urus de Bolivia, del siglo XX al XVI. Ensayo de Historia Regresiva. México D. F.: Fondo de Cultura Económica. 
26 Si Somos Americanos. Revista de Estudios Transfronterizos 